Article

\title{
Electrospun Silk-Boron Nitride Nanofibers with Tunable Structure and Properties
}

\author{
Ye Xue ${ }^{1,2}$ and Xiao $\mathrm{Hu}^{1,2,3, * \text { (D) }}$ \\ 1 Department of Physics \& Astronomy, Rowan University, Glassboro, NJ 08028, USA; xuey5@rowan.edu \\ 2 Department of Biomedical Engineering, Rowan University, Glassboro, NJ 08028, USA \\ 3 Department of Molecular and Cellular Biosciences, Rowan University, Glassboro, NJ 08028, USA \\ * Correspondence: hu@rowan.edu; Tel.: +1-856-256-4860; Fax: +1-856-256-4478
}

Received: 28 March 2020; Accepted: 9 May 2020; Published: 11 May 2020

\begin{abstract}
In this study, hexagonal boron nitride (h-BN) nanosheets and Bombyx mori silk fibroin (SF) proteins were combined and electrospun into BNSF nanofibers with different ratios. It was found that the surface morphology and crosslinking density of the nanofibers can be tuned through the mixing ratios. Fourier transform infrared spectroscopy study showed that pure SF electrospun fibers were dominated by random coils and they gradually became $\alpha$-helical structures with increasing h-BN nanosheet content, which indicates that the structure of the nanofiber material is tunable. Thermal stability of electrospun BNSF nanofibers were largely improved by the good thermal stability of BN, and the strong interactions between $\mathrm{BN}$ and $\mathrm{SF}$ molecules were revealed by temperature modulated differential scanning calorimetry (TMDSC). With the addition of BN, the boundary water content also decreased, which may be due to the high hydrophobicity of BN. These results indicate that silk-based BN composite nanofibers can be potentially used in biomedical fields or green environmental research.
\end{abstract}

Keywords: silk fibroin; hexagonal boron nitride; thermal analysis; glass transition; composite nanofibers

\section{Introduction}

Electrospinning is a unique technique to stretch polymer droplets at high speed by the electrostatic force and then phase-separate polymer chains and solidified them into fibers [1-3]. The physical properties of the fibers-such as diameter, morphology, mechanical strength, crystallinity, and specific surface area - can be controlled by adjusting the parameters of electrospinning such as solution flow rate, voltage, different collection design, and environmental factors (temperature, humidity, etc.) [4]. Controlling the diameter of the fibers also has great effect on their physical properties. When the fiber diameter is relatively large, the specific surface area of the fiber will be small, the arrangement of polymer molecular chains may become less ordered, and more defects on the fiber surface could generally reduce the mechanical strength of the fiber $[2,5]$. When the diameter of the fiber is less than 1 $\mu \mathrm{m}$, the mechanical properties of the nanofiber will be greatly improved since the surface defects of the fiber are reduced [6]. Electrospinning is an effective technique to produce nanofibers with tunable properties that has been used in biomedical science, environmental research, and clean energy in recent years.

Silk protein is a renewable natural material with good biocompatibility and degradability [7-9]. Natural silk fiber has excellent mechanical properties, it has extremely high tensile strength and excellent ductility. These excellent functions make it have good application prospects in the medical fields, such as tissue scaffolds, biosensors, and wound dressings [10-12]. Silk proteins usually come from silkworms and spiders. Different sources of silk proteins lead to different physical and chemical properties. Genetic engineering techniques have also been used to adjust gene sequences 
to manipulate amino acid composition to obtain silk protein materials with new functions [13-15]. The secondary structure of silk protein has also been well studied, and the structure of silk protein can be manipulated through various post-processing methods [16,17]. Natural silk proteins and recombinant silk proteins have been widely used as scaffolds for tissue engineering, as well as microspheres for drug delivery [18-21]. Many biosensors and bioelectronics also require temperature sensors or heat transfer components [22,23]. It was found that the thermal conductivity of silk can be improved by increasing the crystallinity of silk proteins, although it is still much lower than many inorganic materials [24-26]. On the other hand, boron nitride (BN) nanomaterials have excellent thermal stability, thermal conductivity, and stable chemical properties, and have long-term good insulation properties [27-30]. Cell and animal experiments have also shown that boron nitride is not cytotoxic in the proper dosage range and does not have any negative effects on animal signs, which indicates that boron nitride is also biocompatible [31-33]. In recent years, the application of boron nitride in the field of biomedicine has been developed. Functionally modified boron nitride nanoparticles have made significant progress as a tumor drug delivery system [34-36]. However, the hydrophobicity and extremely stable chemical properties of boron nitride nanosheets also limits its biomedical applications as a bulk material [35,37]. Therefore, combining hydrophobic boron nitride and hydrophilic silk protein into a composite material to have additional controllable functions will significantly expand the application range of the material.

In this study, h-BN nanosheets and Bombyx mori silk fibroin protein solutions were electrospun into nanofibers in various mixing ratios. The interaction between the $h-B N$ and protein matrix were studied in detail. The impact of h-BN on the morphology and diameter of electrospun BN-silk fibroin (BNSF) fibers were investigated by scanning electron microscopy (SEM). The effect of h-BN on the secondary structure of silk protein was investigated using Fourier transform infrared spectroscopy (FTIR). Thermal stability and properties of the BNSF electrospun nanofibers were studied using thermogravimetric analysis (TGA) and temperature-modulated differential scanning calorimetry (TM-DSC).

\section{Materials and Methods}

\subsection{Raw Materials}

Bombyx mori silk cocoons were purchased from Treenway Silks (Lakewood, CO, USA). Silk cocoons were firstly degummed by boiling cocoon pieces in a $0.02 \mathrm{M} \mathrm{NaHCO} 3$ (Sigma-Aldrich, St. Louis, MO, USA) solution for $30 \mathrm{~min}$. Then the degummed fibers were rinsed three times in DI water to thoroughly remove the sericin coatings. The rinsed silk fibroin fibers were dried in a vacuum oven at $25{ }^{\circ} \mathrm{C}$ overnight [38,39]. The following materials were used as purchased: formic acid (ACS Grade, 98\%) was purchased from EMD Millipore Corporation (Burlington, MA, USA), calcium chloride (anhydrous, ACS Grade) was purchased from AMRESCO Inc. (Solon, OH, USA), and h-BN nanosheets were purchased from Sigma-Aldrich (St. Louis, MO, USA).

\subsection{Material Synthesis}

Dried silk fibroin (SF) fibers were dissolved in a formic acid solution with $4 \% \mathrm{w} / \mathrm{v}$ calcium chloride at a concentration of $0.15 \mathrm{~g} / \mathrm{mL}$. The SF solution was centrifuged to remove the undissolved residues at $5000 \mathrm{rpm}$ for $10 \mathrm{~min}$. h-BN was added into the solution at various weight ratios to have the BNSF blends with $5 \%, 10 \%, 20 \%, 30 \%, 40 \%$ of BN (For example, $5 \%$ suggests BNSF fibers consist of $95 \mathrm{~g}$ silk protein and $5 \mathrm{~g}$ h-BN). The BNSF solution was shaken with a vortex mixer for $10 \mathrm{~min}$. The thoroughly mixed BNSF solution was then electrospun into nanofibers at a voltage of $20 \mathrm{kV}$ at room temperature and a relative humidity of about $50 \%$. The solution flow rate was controlled at $20 \mu \mathrm{L} / \mathrm{min}$ using a syringe pump (Harvard Apparatus Model 22, Holliston, MA, USA). Electrospun samples were collected every 5 min between two parallel metal plates lined with aluminum foil, placed at $4 \mathrm{~cm}$ from the needle tip. The two parallel plates collecting design can help the solvent evaporate faster and slightly improve the alignment of the fibers as compared to that of the pad collector. In addition, 
free standing fiber mesh samples can be collected directly. The fibers were then dried in a vacuum oven at $40{ }^{\circ} \mathrm{C}$ for $24 \mathrm{~h}$ to remove the acid residues (verified by FTIR).

\subsection{Surface Morphology Analysis}

The electrospun fibers were characterized with a Leo 1530 VP scanning electron microscope (SEM) (Oberkochen, Germany). All samples were sputter-coated with gold before SEM imaging. Experiments were conducted with an accelerating voltage ranging between 10 and $20 \mathrm{kV}$.

\subsection{Structure Analysis}

Structure information of the electrospun fibers was obtained using a Bruker Tensor 27 Fourier transform infrared (FTIR) spectrometer (Billerica, MA, USA). The spectrometer is equipped with a deuterated triglycine sulfate detector, and a multiple reflection, horizontal MIRacle ATR attachment with a Ge crystal (Pike Tech, Madison, WI, USA). A continuously purging nitrogen gas was provided while the experiments were conducted. The spectra were taken at a range of 4000 to $400 \mathrm{~cm}^{-1}$ with 128 background scans and 128 sample scans at a resolution of $4 \mathrm{~cm}^{-1}$. Each sample was characterized at three different spots to ensure homogeneity.

\subsection{Thermal Analysis}

Thermogravimetric analysis (TGA) of BNSF nanofibers was investigated with a TA Instruments Q600 SDT instrument (Wilmington, DE, USA). Each sample weighed between 5-10 mg. Measurements were made from $25^{\circ} \mathrm{C}$ to $600^{\circ} \mathrm{C}$ at a heating rate of $10^{\circ} \mathrm{C} / \mathrm{min}$. All experiments were conducted with continuous nitrogen gas flow rate of $50 \mathrm{~mL} / \mathrm{min}$.

Temperature modulated differential scanning calorimetry (TM-DSC) was conducted with a Q100 calorimeter (TA Instruments, Wilmington, DE, USA) equipped with a refrigerated cooling system. The $\mathrm{N}_{2}$ flow rate was set to $50 \mathrm{~mL} / \mathrm{min}$, and measurements started at $-30{ }^{\circ} \mathrm{C}$ and ended at $400{ }^{\circ} \mathrm{C}$. The temperature increased at a rate of $2{ }^{\circ} \mathrm{C} / \mathrm{min}$ and was modulated every $60 \mathrm{~s}$ at an amplitude of $0.318^{\circ} \mathrm{C}$ to measure the reversing heat capacity.

\section{Results and Discussion}

\subsection{Morphology Study}

SEM analysis was conducted to analyze the morphology and microstructure of the nanofibers (Figure 1). As seen in Figure 1a,b, pure SF nanofibers showed a smooth and uniform surface. For BNSF samples, h-BN nanosheets can be found either immersed into the fiber matrix or spread on the fiber surface. The 5\% BNSF sample showed the best fiber alignment. When the concentration of h-BN is $10 \%$ or higher, it can be seen that the crosslinking density between the fibers is significantly increased (Figure 1e,h,k,n), suggesting the interactions between $\mathrm{h}-\mathrm{BN}$ and silk fibroin molecules become stronger. The $30 \%$ and $40 \%$ BNSF samples have a much rougher surfaces due to the high content of h-BN nanosheets. The pure SF nanofibers had the largest fiber diameter with a size distribution centered around $800 \mathrm{~nm}$, while all other samples showed smaller diameters with an average size of 400-750 nm. 

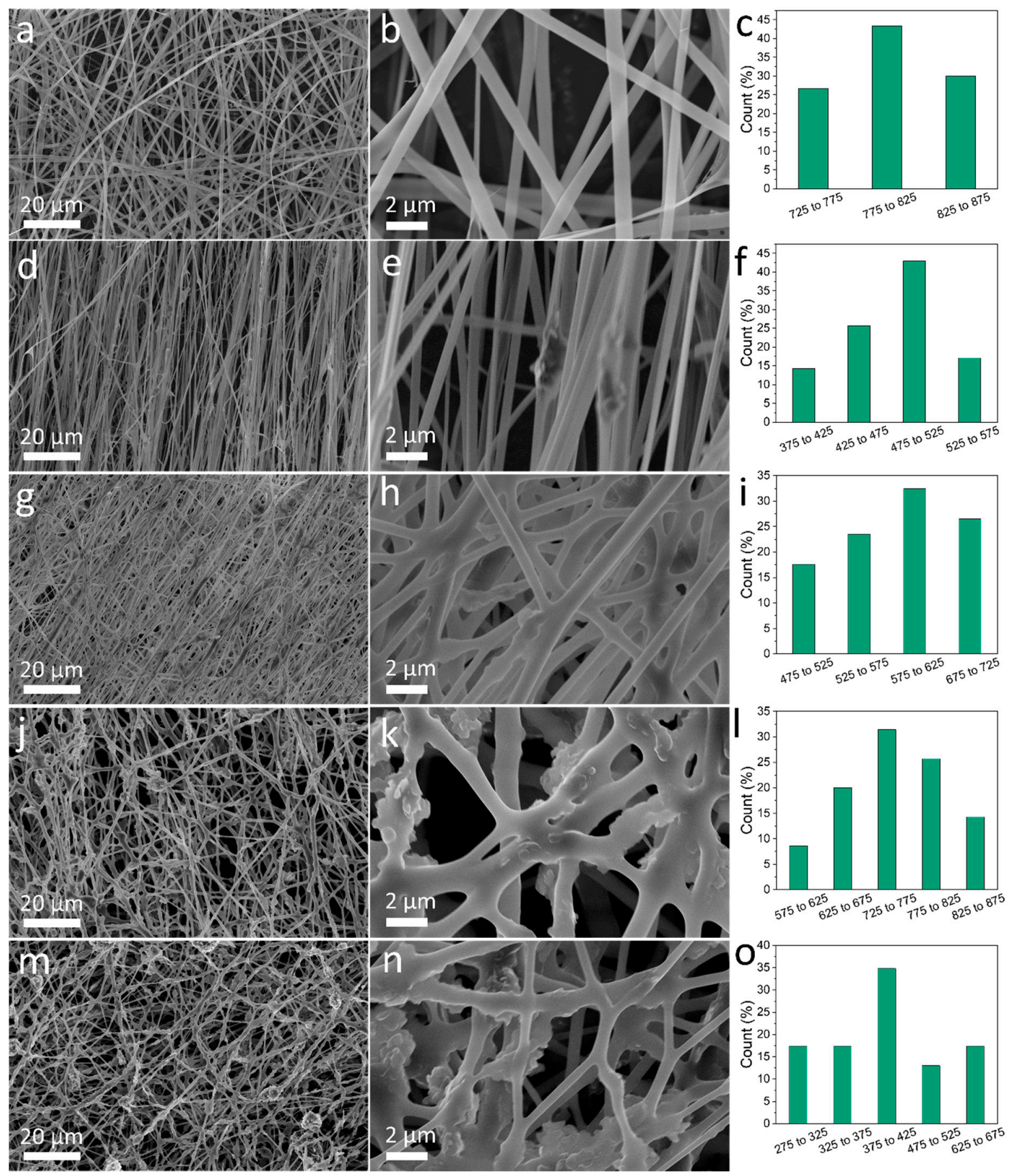

Figure 1. Scanning electron microscopy (SEM) images of pure silk fibroin (SF) (a,b), 5\% boron nitride silk fibroin (BNSF) (d,e), 10\% BNSF (g,h), 30\% BNSF (j, $\mathbf{k})$, and 40\% BNSF (m,n) nanofibers; Quantitative analysis of diameter distribution of pure SF (c), 5\% BNSF (f), 10\% BNSF (i), 30\% BNSF (l), and 40\% BNSF (o) nanofibers.

\subsection{Structural Study}

FTIR spectroscopy was used to characterize the interaction between h-BN and silk fibroin and the secondary structure of silk fibroin (Figure 2). All BNSF samples showed two peaks at 774 and $1364 \mathrm{~cm}^{-1}$, which were attributed to the h-BN sheets $[40,41]$. As the BN content increases, the intensity of these two peaks gradually increases. The raw BN sheets did not show absorbance in the amide I region (1600-1700 $\mathrm{cm}^{-1}$ ), which is mainly related to the secondary structure conformation of the protein. Both the pure SF sample and BNSF samples show a broad amide I peak, while the peak position of the samples shifted from $1649 \mathrm{~cm}^{-1}$ (pure SF) to $1645 \mathrm{~cm}^{-1}$ (40\% BNSF). This indicates that the pure 
SF nanofibers are mainly composed of $\alpha$-helical structure (centered around $1650 \mathrm{~cm}^{-1}$ ), and the high content of BN nanosheets in BNSF fibers can transform part of the secondary structures into random coils (centered around $1640 \mathrm{~cm}^{-1}$ ) [9,16]. During the dissolution and fiber drying process, the $\alpha$-helix structures in the pure SF protein matrix may be disrupted by the BN nanosheets, and stronger hydrogen bonds were formed between the nitrogen atoms of the $\mathrm{BN}$ and the protein chains, which resulted in a reduction in the number of $\alpha$-helixes in BNSF nanofibers [16].
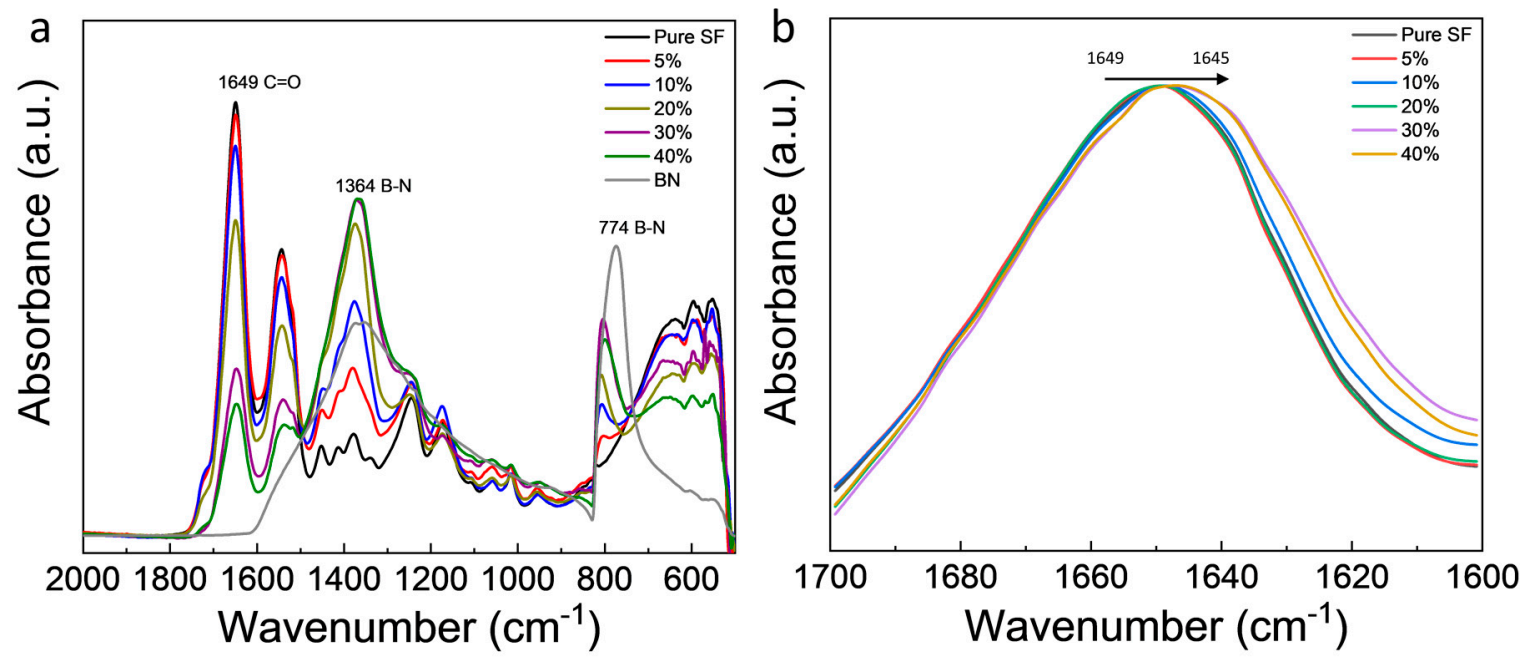

Figure 2. Fourier transform infrared spectroscopy (FTIR) spectra of (a) electrospun pure SF and BNSF nanofibers and raw BN sheets; (b) the amide I region of pure SF and BNSF nanofibers.

\subsection{Thermal Study}

Thermal stability of BNSF nanofibers was first studied by TGA (Figure 3), and their thermal properties are summarized in Table 1. Pure BN was highly thermally stable with only $1.4 \%$ mass loss until $600{ }^{\circ} \mathrm{C}$. In Figure 3, pure SF and BNSF electrospun nanofibers all showed a first mass loss step $\left(T_{\mathrm{w}}-\mathrm{TGA}\right.$ ) around $55^{\circ} \mathrm{C}$ (Figure $3 \mathrm{a}$ ), which is caused by the evaporation of bound water molecules. Silk protein can quickly absorb large amounts of water even in a low humidity environment. The pure SF showed the largest mass loss about $15 \%$ in this region, while the $40 \%$ BNSF sample showed the smallest mass loss about $7.4 \%$. This difference can be attributed to the high hydrophobicity of BN sheets. All samples showed a major degradation temperature around $330{ }^{\circ} \mathrm{C}\left(T_{\mathrm{d}}-\mathrm{TGA}\right.$, Figure $\left.3 \mathrm{~b}\right)$, which is attributed to the major decomposition of the silk proteins. There are two tiny mass loss steps shifting in the degradation region of $200-300^{\circ} \mathrm{C}$, which may be caused by the interactions between the silk protein and the BN. The residual mass of pure SF and BNSF electrospun fibers at $600{ }^{\circ} \mathrm{C}$ is between 43.7-63.6\%, and the residual mass of electrospun fibers increases with the increase of BN content, which suggests that interactions between BN and SF improve the thermal stability of the fibers.

Table 1. Thermal properties of pure silk fibroin (SF) nanofibers, different boron nitride silk fibroin (BNSF) nanofibers, and raw BN sheets.

\begin{tabular}{|c|c|c|c|c|c|c|c|}
\hline Sample & $\begin{array}{c}\text { Bound Water } \\
\text { (\%)-TGA }\end{array}$ & $\begin{array}{c}T_{w} \\
\left({ }^{\circ} \mathrm{C}\right)-\mathrm{TGA}\end{array}$ & $\begin{array}{c}T_{\mathrm{w}} \\
\left({ }^{\circ} \mathrm{C}\right)-\mathrm{DSC}\end{array}$ & $\begin{array}{c}T_{\mathrm{g}} \\
\left({ }^{\circ} \mathrm{C}\right)-\mathrm{DSC}\end{array}$ & $\begin{array}{c}T_{\mathrm{d}} \\
\left({ }^{\circ} \mathrm{C}\right)-\mathrm{TGA}\end{array}$ & $\begin{array}{c}T_{\mathrm{d}} \\
\left({ }^{\circ} \mathrm{C}\right)-\mathrm{DSC}\end{array}$ & $\begin{array}{c}\text { Mass Remaining\% } \\
\text { at } 600^{\circ} \mathrm{C}\end{array}$ \\
\hline Pure SF & 13.6 & 50.8 & 66.2 & 204.9 & 332.2 & 319.0 & 43.7 \\
\hline $10 \%$ BNSF & 8.5 & 57.9 & 71.3 & 177.9 & 331.6 & 321.3 & 50.5 \\
\hline $20 \%$ BNSF & 10.8 & 49.5 & 89.7 & 185.6 & 328.5 & 321.3 & 55.5 \\
\hline $30 \%$ BNSF & 8.4 & 54.2 & 74.4 & 189.5 & 339.1 & 327.2 & 58.2 \\
\hline
\end{tabular}

${ }^{*}$ All temperature values have an error bar within $\pm 0.5^{\circ} \mathrm{C}$; Mass remaining \% data is obtained from TG analysis. 

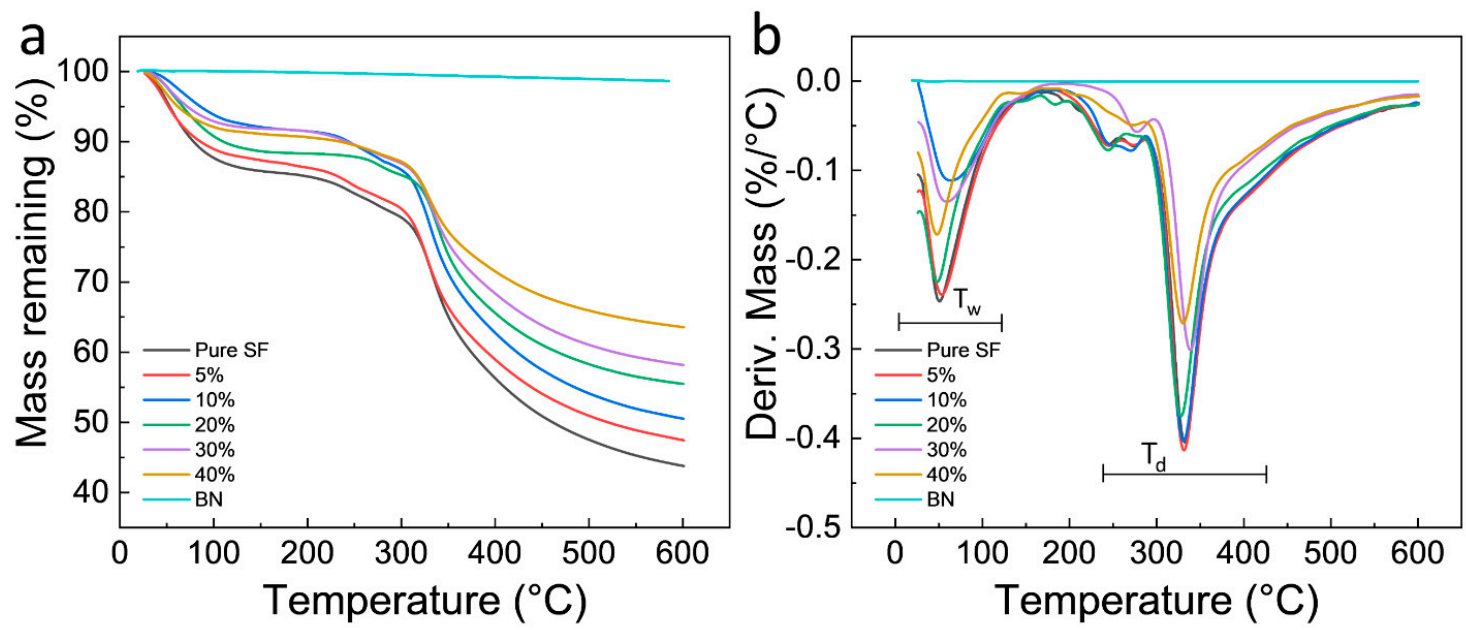

Figure 3. Thermogravimetric curves of (a) electrospun BNSF nanofibers and raw BN sheets; (b) displays the first derivative thermogravimetry (DTG) curves of the samples.

Heat flow curves from TM-DSC scans (Figure 4a) confirmed the bounding water evaporation and protein decomposition temperatures from TGA. The peaks from bounding water evaporation $\left(T_{\mathrm{w}}-\mathrm{DSC}\right)$ are much broader than the protein decomposition peaks ( $\left.T_{\mathrm{d}}-\mathrm{DSC}\right)$, and the pure SF fibers showed the lowest $\mathrm{T}_{\mathrm{w}}$ peak compared to all BNSF fibers, indicating the interaction between SF and BN molecules has significant impact on their bound water. Reversing heat capacity curves (Figure $4 \mathrm{~b}$ ) showed that pure SF has the highest onset glass transition temperature at about $120^{\circ} \mathrm{C}$, while $40 \%$ BNSF has the lowest onset glass transition temperature at about $96^{\circ} \mathrm{C}$. This suggests that amorphous components such as random coils in silk fibroin gained more mobility when combined with $\mathrm{BN}$ nanosheets. The thermal properties obtained from TM-DSC (water evaporation peak temperature, $T_{\mathrm{w}}$-DSC; glass transition temperature, $T_{\mathrm{g}}$-DSC; and thermal degradation peak temperature, $T_{\mathrm{d}}-\mathrm{DSC}$ ) are also summarized in Table 1. The glass transition temperature of pure SF is higher than those of BNSF samples, indicating that the random coil structure in BNSF nanofibers can significantly improve the flexibility of the material.
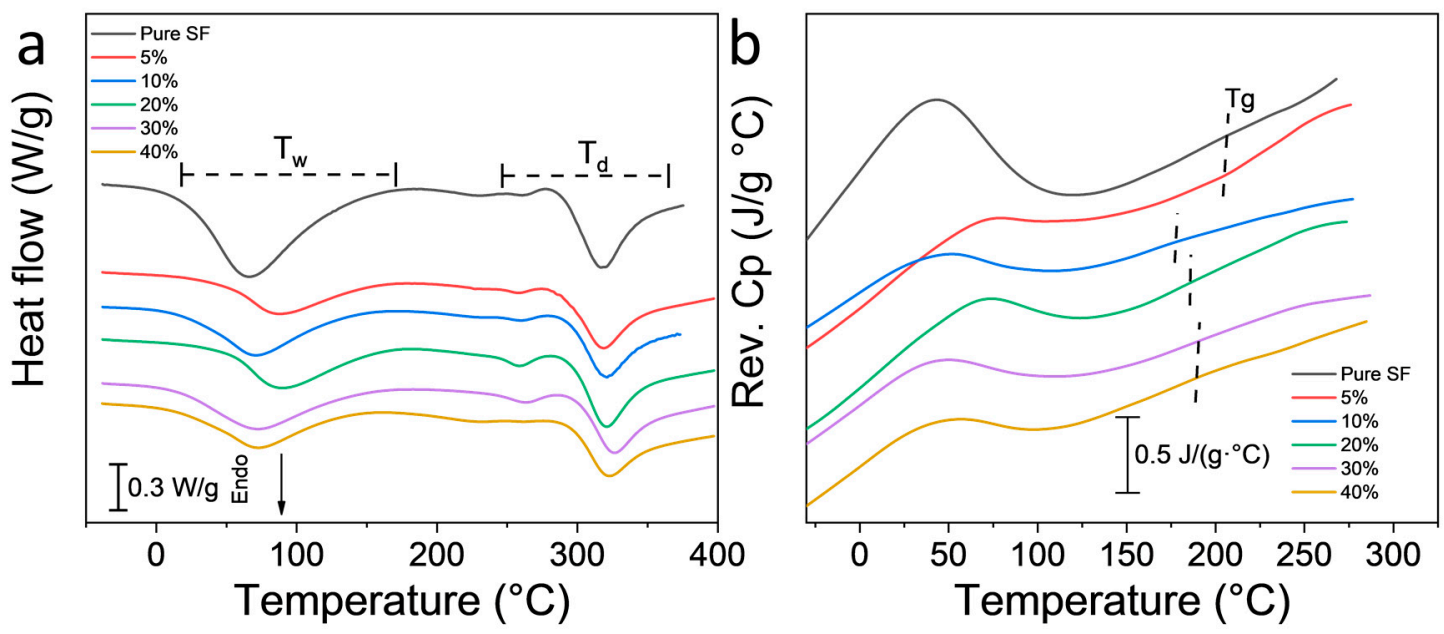

Figure 4. (a) Total heat flow curves of electrospun SF and BNSF nanofibers; (b) the reversing heat capacity curves of BNSF nanofibers. The scans were at a rate of $2{ }^{\circ} \mathrm{C} / \mathrm{min}$ and temperature was modulated every $60 \mathrm{~s}$ at an amplitude of $0.318^{\circ} \mathrm{C}$. 


\subsection{Mechanism of Self-Assembly}

Based on the results of secondary structure analysis from FTIR and the thermal analysis from TGA and DSC, a mechanism of self-assembly for the BNSF nanofiber materials is proposed in Figure 5. As discussed in Figure 2, pure SF and BNSF samples showed a peak shift between 1645 and $1649 \mathrm{~cm}^{-1}$, which indicated that the electrospun pure silk fibers are rich in $\alpha$-helical structures [16,42]. After adding the BN nanosheets, the peak shifted to a lower wavelength, which suggested that the $\alpha$-helix structure in the protein matrix is reduced and the random coil structure is increased [16]. The hydrogen bonds between $\mathrm{BN}$ molecules and the protein backbones can effectively disrupt the $\alpha$-helix structures and transform them into random coil structures (Figure $5 b$ ). Meanwhile, these hydrogen bonds between $\mathrm{BN}$ and SF proteins at different locations will also increase the numbers of crosslinks between the nanofibers, as shown in the SEM (Figure 1). The smaller and more dispersed distribution of $\alpha$-helices resulted in higher mobility of the amorphous components, which in turn resulted in broader and lower glass transition temperatures of the composite nanofibers (Figure 4) [43].

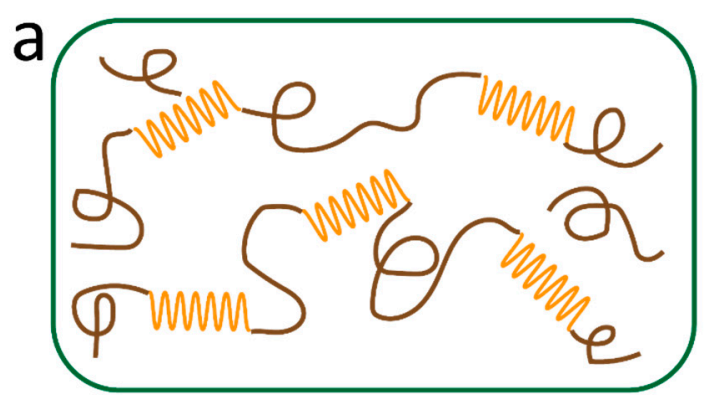

WWM $\alpha$-helix

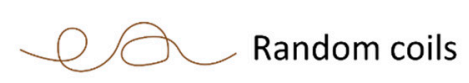

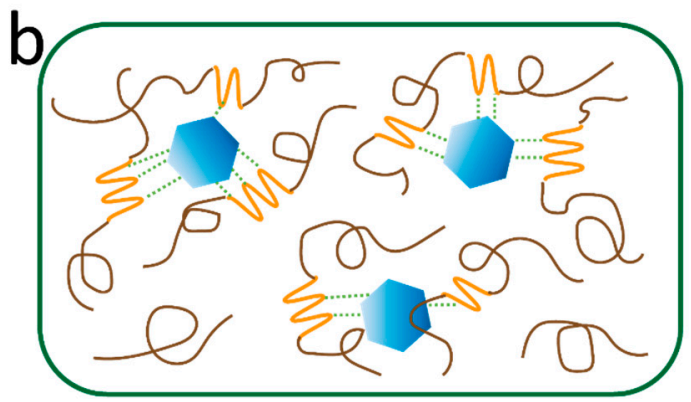

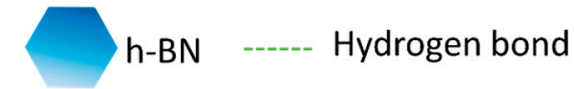

Figure 5. Self-assembled structures of (a) electrospun pure SF nanofibers; (b) electrospun BNSF nanofibers, showing that the BN nanosheets disrupted the secondary structures of silk fibroin proteins.

\section{Conclusions}

In this study, the interactions between h-BN nanosheets and silk fibroin proteins in their electrospun nanofibers were investigated. The morphology and microstructure of the electrospun fibers were observed using SEM. Pure SF sample showed a smooth fiber surface with uniform fiber diameter. Electrospun fibers with a high BN content (over 10\%) showed rougher surface morphology and higher fiber crosslinking density. FTIR results showed that BN molecules can form hydrogen bonds with silk proteins and transform the $\alpha$-helical structure of pure SF into random coils, which suggests that the composite material has better flexibility. Due to the high hydrophobicity of BN and the strong interaction of SF-BN, pure SF samples showed the highest bound water content in TGA study and the lowest bound water evaporation temperature in DSC study. The good thermal stability of BN can significantly improve the thermal stability of electrospun BNSF fibers, and a self-assembly mechanism of electrospun BNSF nanofiber materials is proposed.

Author Contributions: Y.X and X.H. conceived and designed the experiments; Y.X. performed the experiments; and Y.X. and X.H. analyzed the data and wrote the paper. All authors have read and agreed to the published version of the manuscript.

Funding: This study was supported by Rowan University Seed Research Grants. X.H. is also supported by the US NSF Biomaterials Program (DMR-1809541).

Conflicts of Interest: The authors declare no conflict of interest. 


\section{References}

1. Conte, A.A.; Shirvani, K.; Hones, H.; Wildgoose, A.; Xue, Y.; Najjar, R.; Hu, X.; Xue, W.; Beachley, V.Z. Effects of post-draw processing on the structure and functional properties of electrospun PVDF-HFP nanofibers. Polymer 2019, 171, 192-200. [CrossRef]

2. Beachley, V.; Wen, X. Polymer nanofibrous structures: Fabrication, biofunctionalization, and cell interactions. Prog. Polym. Sci. 2010, 35, 868-892. [CrossRef]

3. Frenot, A.; Chronakis, I.S. Polymer nanofibers assembled by electrospinning. Curr. Opin. Colloid Interface Sci. 2003, 8, 64-75. [CrossRef]

4. Beachley, V.; Wen, X. Effect of electrospinning parameters on the nanofiber diameter and length. Mater. Sci. Eng. C 2009, 29, 663-668. [CrossRef]

5. Beachley, V.; Katsanevakis, E.; Zhang, N.; Wen, X. Highly aligned polymer nanofiber structures: Fabrication and applications in tissue engineering. In Biomedical Applications of Polymeric Nanofibers; Springer: Berlin/Heidelberg, Germany, 2011; pp. 171-212.

6. Huang, Z.-M.; Zhang, Y.-Z.; Kotaki, M.; Ramakrishna, S. A review on polymer nanofibers by electrospinning and their applications in nanocomposites. Compos. Sci. Technol. 2003, 63, 2223-2253. [CrossRef]

7. Xue, Y.; Wang, F.; Torculas, M.; Lofland, S.; Hu, X. Formic Acid Regenerated Mori, Tussah, Eri, Thai, and Muga Silk Materials: Mechanism of Self-Assembly. ACS Biomater. Sci. Eng. 2019, 5, 6361-6373. [CrossRef]

8. Wang, F.; Wu, H.; Venkataraman, V.; Hu, X. Silk fibroin-poly (lactic acid) biocomposites: Effect of protein-synthetic polymer interactions and miscibility on material properties and biological responses. Mater. Sci. Eng. C 2019, 104, 109890. [CrossRef]

9. Lu, Q.; Hu, X.; Wang, X.; Kluge, J.A.; Lu, S.; Cebe, P.; Kaplan, D.L. Water-insoluble silk films with silk I structure. Acta Biomater. 2010, 6, 1380-1387. [CrossRef]

10. Mandal, B.B.; Grinberg, A.; Gil, E.S.; Panilaitis, B.; Kaplan, D.L. High-strength silk protein scaffolds for bone repair. Proc. Natl. Acad. Sci. USA 2012, 109, 7699-7704. [CrossRef]

11. Pal, R.K.; Farghaly, A.A.; Wang, C.; Collinson, M.M.; Kundu, S.C.; Yadavalli, V.K. Conducting polymer-silk biocomposites for flexible and biodegradable electrochemical sensors. Biosens. Bioelectron. 2016, 81, $294-302$. [CrossRef]

12. Baoyong, L.; Jian, Z.; Denglong, C.; Min, L. Evaluation of a new type of wound dressing made from recombinant spider silk protein using rat models. Burns 2010, 36, 891-896. [CrossRef]

13. Tokareva, O.; Jacobsen, M.; Buehler, M.; Wong, J.; Kaplan, D.L. Structure-function-property-design interplay in biopolymers: Spider silk. Acta Biomater. 2014, 10, 1612-1626. [CrossRef]

14. Dinjaski, N.; Kaplan, D.L. Recombinant protein blends: Silk beyond natural design. Curr. Opin. Biotechnol. 2016, 39, 1-7. [CrossRef]

15. Frandsen, J.L.; Ghandehari, H. Recombinant protein-based polymers for advanced drug delivery. Chem. Soc. Rev. 2012, 41, 2696-2706. [CrossRef]

16. Hu, X.; Kaplan, D.; Cebe, P. Determining beta-sheet crystallinity in fibrous proteins by thermal analysis and infrared spectroscopy. Macromolecules 2006, 39, 6161-6170. [CrossRef]

17. Stanton, J.; Xue, Y.; Pandher, P.; Malek, L.; Brown, T.; Hu, X.; Salas-de la Cruz, D. Impact of ionic liquid type on the structure, morphology and properties of silk-cellulose biocomposite materials. Int. J. Biol. Macromol. 2018, 108, 333-341. [CrossRef]

18. Wang, X.; Yucel, T.; Lu, Q.; Hu, X.; Kaplan, D.L. Silk nanospheres and microspheres from silk/pva blend films for drug delivery. Biomaterials 2010, 31, 1025-1035. [CrossRef]

19. Wang, X.; Wenk, E.; Hu, X.; Castro, G.R.; Meinel, L.; Wang, X.; Li, C.; Merkle, H.; Kaplan, D.L. Silk coatings on PLGA and alginate microspheres for protein delivery. Biomaterials 2007, 28, 4161-4169. [CrossRef]

20. Lammel, A.; Schwab, M.; Hofer, M.; Winter, G.; Scheibel, T. Recombinant spider silk particles as drug delivery vehicles. Biomaterials 2011, 32, 2233-2240. [CrossRef]

21. Wu, J.; Xie, X.; Zheng, Z.; Li, G.; Wang, X.; Wang, Y. Effect of pH on polyethylene glycol (PEG)-induced silk microsphere formation for drug delivery. Mater. Sci. Eng. C 2017, 80, 549-557. [CrossRef]

22. Nambiar, S.; Yeow, J.T. Conductive polymer-based sensors for biomedical applications. Biosens. Bioelectron. 2011, 26, 1825-1832. [CrossRef] [PubMed]

23. Prakash, S.; Chakrabarty, T.; Singh, A.K.; Shahi, V.K. Polymer thin films embedded with metal nanoparticles for electrochemical biosensors applications. Biosens. Bioelectron. 2013, 41, 43-53. [CrossRef] [PubMed] 
24. Xue, Y.; Lofland, S.; Hu, X. Thermal conductivity of protein-based materials: A review. Polymers 2019, 11, 456. [CrossRef] [PubMed]

25. Huang, X.; Liu, G.; Wang, X. New secrets of spider silk: Exceptionally high thermal conductivity and its abnormal change under stretching. Adv. Mater. 2012, 24, 1482-1486. [CrossRef] [PubMed]

26. Zhang, L.; Chen, T.; Ban, H.; Liu, L. Hydrogen bonding-assisted thermal conduction in $\beta$-sheet crystals of spider silk protein. Nanoscale 2014, 6, 7786-7791. [CrossRef]

27. Wu, Y.; Xue, Y.; Qin, S.; Liu, D.; Wang, X.; Hu, X.; Li, J.; Wang, X.; Bando, Y.; Golberg, D. BN nanosheet/polymer films with highly anisotropic thermal conductivity for thermal management applications. ACS Appl. Mater. Interfaces 2017, 9, 43163-43170. [CrossRef]

28. Wang, J.; Wu, Y.; Xue, Y.; Liu, D.; Wang, X.; Hu, X.; Bando, Y.; Lei, W. Super-compatible functional boron nitride nanosheets/polymer films with excellent mechanical properties and ultra-high thermal conductivity for thermal management. J. Mater. Chem. C 2018, 6, 1363-1369. [CrossRef]

29. Guerra, V.; Wan, C.; McNally, T. Thermal conductivity of 2D nano-structured boron nitride (BN) and its composites with polymers. Prog. Mater. Sci. 2019, 100, 170-186. [CrossRef]

30. Zeng, X.; Sun, J.; Yao, Y.; Sun, R.; Xu, J.-B.; Wong, C.-P. A combination of boron nitride nanotubes and cellulose nanofibers for the preparation of a nanocomposite with high thermal conductivity. ACS Nano 2017, 11, 5167-5178. [CrossRef]

31. Kıvanç, M.; Barutca, B.; Koparal, A.T.; Göncü, Y.; Bostanc1, S.H.; Ay, N. Effects of hexagonal boron nitride nanoparticles on antimicrobial and antibiofilm activities, cell viability. Mater. Sci. Eng. C 2018, 91, 115-124. [CrossRef]

32. Li, X.; Wang, X.; Zhang, J.; Hanagata, N.; Wang, X.; Weng, Q.; Ito, A.; Bando, Y.; Golberg, D. Hollow boron nitride nanospheres as boron reservoir for prostate cancer treatment. Nat. Commun. 2017, 8, 1-12. [CrossRef]

33. Li, L.; Li, J.; Shi, Y.; Du, P.; Zhang, Z.; Liu, T.; Zhang, R.; Liu, Z. On-Demand Biodegradable Boron Nitride Nanoparticles for Treating Triple Negative Breast Cancer with Boron Neutron Capture Therapy. ACS Nano 2019, 13, 13843-13852. [CrossRef]

34. Feng, S.; Zhang, H.; Yan, T.; Huang, D.; Zhi, C.; Nakanishi, H.; Gao, X.-D. Folate-conjugated boron nitride nanospheres for targeted delivery of anticancer drugs. Int. J. Nanomed. 2016, 11, 4573.

35. Cheng, C.-C.; Muhabie, A.A.; Huang, S.-Y.; Wu, C.-Y.; Gebeyehu, B.T.; Lee, A.-W.; Lai, J.-Y.; Lee, D.-J. Dual stimuli-responsive supramolecular boron nitride with tunable physical properties for controlled drug delivery. Nanoscale 2019, 11, 10393-10401. [CrossRef]

36. Permyakova, E.S.; Sukhorukova, I.V.; Antipina, L.Y.; Konopatsky, A.S.; Kovalskii, A.M.; Matveev, A.T.; Lebedev, O.I.; Golberg, D.V.; Manakhov, A.M.; Shtansky, D.V. Synthesis and characterization of folate conjugated boron nitride nanocarriers for targeted drug delivery. J. Phys. Chem. C 2017, 121, 28096-28105. [CrossRef]

37. Saleh, D.A.; Niskanen, J.; Xue, Y.; Golberg, D.; Winnik, F.M.; Sosnik, A. Boron nitride nanotube-based amphiphilic hybrid nanomaterials for superior encapsulation of hydrophobic cargos. Mater. Today Chem. 2017, 6, 45-50. [CrossRef]

38. Xue, Y.; Jao, D.; Hu, W.; Hu, X. Silk-silk blend materials. J. Therm. Anal. Calorim. 2017, 127, $915-921$. [CrossRef]

39. Callaway, K.A.; Xue, Y.; Altimari, V.; Jiang, G.; Hu, X. Comparative investigation of thermal and structural behavior in renewably sourced composite films of even-even nylons (610 and 1010) with silk fibroin. Polymers 2018, 10, 1029. [CrossRef]

40. Muratov, D.; Kuznetsov, D.; Il'Inykh, I.; Burmistrov, I.; Mazov, I. Thermal conductivity of polypropylene composites filled with silane-modified hexagonal BN. Compos. Sci. Technol. 2015, 111, 40-43. [CrossRef]

41. Harrison, H.; Lamb, J.T.; Nowlin, K.S.; Guenthner, A.J.; Ghiassi, K.B.; Kelkar, A.D.; Alston, J.R. Quantification of hexagonal boron nitride impurities in boron nitride nanotubes via FTIR spectroscopy. Nanoscale Adv. 2019, 1, 1693-1701. [CrossRef] 
42. Hu, X.; Cebe, P.; Weiss, A.S.; Omenetto, F.; Kaplan, D.L. Protein-based composite materials. Mater. Today 2012, 15, 208-215. [CrossRef]

43. Hu, X.; Shmelev, K.; Sun, L.; Gil, E.-S.; Park, S.-H.; Cebe, P.; Kaplan, D.L. Regulation of silk material structure by temperature-controlled water vapor annealing. Biomacromolecules 2011, 12, 1686-1696. [CrossRef] [PubMed] 